\title{
Effects of a Program of Sport Schools on Development of Social and Psychomotor Skills of People with Autistic Spectrum Disorders: A Pilot Project
}

\author{
José María López ${ }^{1}$, Ricardo Moreno-Rodríguez ${ }^{1}$, Carlos-María Alcover ${ }^{2}$, Inmaculada Garrote ${ }^{1}$, Sergio Sánchez ${ }^{3}$ \\ ${ }^{1}$ Unit of Attention for People with disabilities and special educational needs, Rey Juan Carlos University, Madrid, Spain \\ ${ }^{2}$ Faculty of Health Sciences, Rey Juan Carlos University, Madrid, Spain \\ ${ }^{3}$ Faculty of Education, Burgos University, Burgos, Spain
}

Correspondence: Ricardo Moreno-Rodríguez, Unit of Attention for People with disabilities and special educational needs, Rey Juan Carlos University, 28933 Móstoles, Madrid, Spain.

Received: July 5, 2017 Accepted: July 23, $2017 \quad$ Online Published: July 27, 2017

doi:10.11114/jets.v5i8.2555 URL: https://doi.org/10.11114/jets.v5i8.2555

\begin{abstract}
Individuals with Autistic Spectrum Disorder (ASD) present learning difficulties and limited performance of social skills, besides lower motor skills performance in comparison with their peers. Owing to these difficulties, most of children with ASD are at risk of social exclusion or a poor inclusion due to their behavior, mainly playing with other partners, understanding play and leisure as a main performance area for children and their main occupation during childhood (defining occupation from occupational therapy point of view). Therefore, learning rules of a well-known game such as football, together with social skills training can help avoid exclusion and improve social life of people with ASD. Two of the main objectives pursued by this study are: first, to favor football practice among children with different abilities, as well as their future inclusion in the rest of social sports schools performing the activities at the same level as their peers; and, secondly, to facilitate comprehensive development for young people in order to improve their quality of life, moreover, the creation of healthy and sporting habits.

It is now presented a pilot project $(\mathrm{n}=5)$ in which the actions carried out during the training program are analyzed along with the results achieved after 24 one-hour-session. In general terms, the results obtained are positive with the best scores in psychomotor and social skills at the end of the programs, being conscious of this study's limitations.
\end{abstract}

Keywords: TEA, football, disability, social abilities, motor abilities

\section{Introduction}

\subsection{Introduce the Problem}

Autism Spectrum Disorders (ASD) are defined by the Diagnostic and Statistical Manual of Mental Disorders (DSM) in its fifth edition (American Psychiatric Association, 2013) as a set of diagnostic criteria belonging to the psychological disorders included in a major category, that is, the neurodevelopmental disorders. ASD is increasingly arousing interest over the last decades (Smith et al., 2007).

In a review of prevalence studies carried out until 2004 and divided into two main periods (that is, from 1966 to 1994 , and a second period from 1995 to 2004), Fombonne (2005) found out that the median prevalence rate of ASD is 4,7/10.000 in the 18 published studies from 1966 to 1994; while in the second period as detailed above, the median prevalence rate is $12,7 / 10.000$. On the basis of the analysis of the studies carried out from 1987 by Fombonne, the conservative prevalence estimates are 13/10.000 for the Autistic Spectrum Disorders. Only 6 years later, new prevalence studies were incorporated in the analysis previously mentioned, where the prevalence estimates of ASD rise to 22/10.000 (Fombonne, Quirke y Hagen, 2011). This increase may be due to the improved identification and the broadening of diagnostic criteria, among other factors.

These disorders appear during childhood, showing cognitive and behavioural displays throughout human development. These displays are mainly observed in social areas as well as in everyday life of people with this diagnosis. In most cases, these disorders cause restrictions on personal autonomy and besides reaching certain degree of disability (Díez-Cuervo et al., 2005). 
The scientific study of this type of disorders remains a challenge due to a number of reasons among with the lack of a well-defined etiological model and the increase in prevalence of autism spectrum disorders in the last few years stand out. Other significant reasons that hinder the work of professionals are the heterogeneity and severity of these disorders that often appear early in development (Fuentes-biggi, Ferrari-arroyo, Boada-muñoz, Touriño-aguilera, Martos, et al., 2006) as pointed out above.

Nowadays, there are different types of programs and protocols which can be put into practice with scientific evidence available -though/but scarce- about the treatment results to achieve operational improvements for people with ASD. For instance: sensorimotor treatments based on the development of perceptual and motor skills; psychoeducational and psychological approaches focused on the implementation of cognitive behavioural therapy techniques and social skills; Augmentative and Alternative Communication Systems which modify the medium of expression for people with ASD, using pictographs or alternative mechanisms to communicate with others; biomedical treatments, underpinned by the use of medicine to obtain control over brain function and consequently operational improvement (Fuentes-biggi, Ferrari-arroyo, Boada-muñoz, Touriño-aguilera, Martos, et al., 2006). The examination of the results obtained from the application of the different programs highlights the necessity of the development of individualized programs paying attention to the characteristics and progress of individuals with ASD (Fuentes-biggi, Ferrari-arroyo, Boada-muñoz, Touriño-aguilera, Martos, et al., 2006).

It can be considered that applying the same treatment to two individuals with ASD is not effective enough. However, if the treatment is adjusted to the needs, motivations and development of the person with ASD, although sharing a common basis, the treatment could be more effective.

\subsection{Importance of the Problem}

Sport for people with ASD is one of the therapies that has started to be introduced over the last years. This therapy combines in the same manner aspects from sensorimotor treatments and treatments addressed to the development of social field. In addition to being a daily activity among children, sport entails diverse advantages in comparison to other current techniques used. Nevertheless, there is not enough research to assess its effectiveness.

As Brandon (1999) stands out, physical activity and sports are non-pharmacological therapies effective to reduce stress, sleep disorders, depression and anxiety, as well as other impairments emerged throughout the aging process.

A research about physical activity and the development of children's self-esteem was undertaken by Gruber (1986) who found evidence of a positive impact on the implementation of this variable. It may also be highlighted this positive effect had higher impact on people with disabilities, moreover, physical activities showed a positive influence on the self-esteem of the investigation subjects.

Therefore, sport stipulates a set of rules and objectives which distinguish it from play, although sport also shares with play the ludic function. It is important to mention that both terms are used interchangeably during early childhood (Puerta, 2005). Institutionally, there are three recognizable aspects with regard to sport:

- Citizen's sport practice as a spontaneous, selfless and recreational activity, sometimes aiming at educational and medical purposes.

- Sporting activities organized by voluntary organizations.

- An increasing movement towards professionalization and commercialization that has emerged from sport events $-\mathrm{a}$ mass phenomenon-

Formal sports referred to in this article correspond to the institutional aspect, context in which sport is guaranteed and regulated by Sports Associations, which should be guided by the adequate administrative and control structures (Estado, 2003).

The importance of sports is enshrined in the current Spanish legislation established as "one of the most deep-rooted social activities because of its capacity for striking and mobilization" "essential component of the educational system" considering its practice as "fundamental for maintaining health, thus, sport is a factor that corrects social imbalances and contributes to equality among citizens, as well as, creator of habits which favour social inclusion; and, additionally, teamwork encourages solidarity". These same conclusions have been reached from the study of physical activity and sports in different areas of the investigation, such as education (Gutiérrez Sanmartín, 2004), health sciences, and of great importance in this study (Ibáñez López \& Mudarra Sánchez, 2004; Lagar García, 2003) psychology (Dosil, 2004).

Conversely, from the occupational perspective -with regard to children- the main area of occupational performance is play; so, providing sports practice as part of children participation is fundamental to obtain results and progress on the practice and development of specific skills, all this heightened by sports.

Particularly, in the case of children with ASD is especially relevant to pay attention to this area, together with 
entertainment and the promotion of access to sports activities being aware of the characteristics of this group of individuals (Gutiérrez Sanmartín, 2004).

The comparison of children with ASD and typically developing children indicates that those with ASD get less physical activity, mainly due to fewer opportunities and adaptations in order to guarantee their participation and performance.

The objectives for the study are as follows:

- To favor football practice among children with different abilities, as well as their future inclusion in the rest of social sports schools performing the activities at the same level as their peers.

- To facilitate comprehensive development for young people in order to improve their quality of life, moreover, the creation of healthy and sporting habits.

- To contribute to the development of cognitive, motor and socio-affective skills and abilities promoting educational values of football practice.

- To strengthen inherent aspects of sports in favor of effectively encouraging the participants of this project.

\subsection{Relevant Scholarship}

Following the study carried out by Memari, (Memari et al., 2013) where physical activity in children with ASD was analyzed, the authors affirmed that one of the main reasons for lower participation of children with ASD in physical activities and games, in comparison to typically developing children, is their difficulty in assimilating the rules and their consequent frustration.

By focusing on physical activity in children with ASD out of schools hours, it highlights the limited time available for this activity. In addition, the study carried out by Obrusnikova \& Cavalier (Obrusnikova \& Cavalier, 2010) where barriers and facilitators to physical activity in children with ASD out of school hours were assessed. It is concluded that they do not have adequate time to perform physical activity besides the difficulties these children have to exercise activities which imply a great deal of coordination and gross and fine motor skills.

Three main barriers/obstacles were identified and classified: intrapersonal, interpersonal, constitutional, communautaire and physical.

1) Physical Activity impact on social disruptions in children with ASD.

Many studies have been carried out by researchers that state the benefits of sport for individuals with ASD. The following is a brief explanation of those benefits.

First of all, a research by MacDonald (Lloyd, MacDonald \& Lord, 2013) wanted to prove whether motor skills in children with ASD contributed to achieve successful communicative skills. The researchers presented the hypothesis that children with excellent motor skills competence will also show good social and communicative skills. The results reported that those children, who reflected more difficulties to perform motor skills activities, also presented more deficits with regard to social interaction during the completion of the TGMD-2 test.

Similarly, Darcy S. VonderHulls, Lisa K. Walker \& Janet M. Powell (2006) carried out a study through aquatic therapy. The results revealed that those participants with better-developed motor skills showed higher social participation.

Furthermore, Chien-Yu Pan (2006) wanted to compare the physical activity levels among children with ASD and typically developing children during study breaks. The results reported that activities during study breaks had less participation of children with ASD; thus, it is concluded that the main reason is: these children can choose the type of activity, consequently, they prefer those leisure activities which don't involve social interaction.

2) Physical Activity impact on motor skills.

A great percentage of children with ASD show a number of motor deficits that negatively affect on their daily life.

Occasionally, differences in motor skills between children with ASD and typically developing children are significant, having as a result restrictions on joint physical activity.

This disorder in young people affects person's coordination of both sides of the body, including their legs and arms (Staples \& Reid, 2010).

Another study by Jasmin et al. (Jasmin et al., 2009) wanted to state the sensorimotor skills impact on daily life activities considering children with ASD; those individuals who show less development of gross and fine motor skills. The results revealed that children having problems with fine motor skills have problems in daily life activities which require fine motor ability, such as toileting or dressing.

On the other side, Vonder Hulls et al., (2006) drew up and carried out an aquatic physical exercise program. The 
researchers observed an increase of mobility and coordination of upper limbs; moreover, it was confirmed an increase in the efficiency of daily life skills and other abilities such as strength and flexibility.

We have chosen football for the realization of this pilot project owing to its sporting and social values (Martínez et al., 1996). Football is considered the king of sports, known and practiced by millions of people worldwide. Even so, football needs a number of concepts and skills acquired through training. At the conceptual level, football also requires theoretical and practical aspects and the knowledge of a series of rules which are a fundamental contribution to improve our capacity of football. In the physical level, it will be trained technical, tactical and physical concepts, as being responsible for the fulfillment of the entire preparation (Gómez López, Valero Valenzuela, Peñalver López \& Velasco da Silva, 2008).

At a technical level, we will put into practice technical actions during a basic training session, for instance, goal kick, one-touch pass, ball control and ball carrier. At both strategic and tactic levels, we will focus on play form and manner. From a physical perspective, we will develop basic physical qualities (endurance, flexibility, strength and speed) as well as motor skills, for example, jumping, turns, running, throwing, kicking and catching (Cos, Cos, Buenaventura, Pruna \& Ekstrand, 2010).

Taking into acoount the social and psychological area, it is important to stand out that football promotes values such as tolerance, solidarity, respect, fellowship, equality, teamwork, empathy, communication, generosity, among other, meanwhile individuals get sports practice experience (Nuñez Del Arco, s. f.).

\subsection{Hypotheses}

The participants of the program will show improvement in their motor skills implementation besides an improvement in their social skills implementation.

\section{Method}

\subsection{Participants}

The sample was selected on the basis of the replies received to the publication of this project imminent fulfillment, addressed to children with the following characteristics:

- Between 6-12 years of age.

- Individuals with an ASD diagnosis (Asperger's Syndrome or High-Functioning Autism).

- Preserved verbal communication or at least speech comprehension.

- The intensity of supports required should not interfere with the development of activities or the autonomous participation.

\subsection{Procedure}

A football training program was undertaken with standardized objectives. The adaptation and monitoring of this program was carried out by educational professionals, specialized in Physical Education and with expertise in children with ASD. All professionals belong to the Rey Juan Carlos University and Real Madrid Foundation. The adaptations made include decision-making processes about the exercises that should be carried out and the individual adaptations to each and every participant; moreover, the monitoring during the implementation of the program and possible changes in team dynamics.

Both the objectives and methodology are the same that those used with children in the same age group, with or without disabilities. The ultimate objectives pursued were adopted removing any competitive aspect (not the cooperative) because of the nature and duration of the program (a 3-month pilot project, one hour sessions, two days per week from the beginning). The sessions took place in the soccer field with all the necessary equipment, such as: soccer balls, equipment goals, cones, etc.

Semi-structured interviews were carried out to know child functioning level. Those interviews were conducted in the presence of parents. The total number of respondents was 10 children, but finally 9 participants were included in this program. Excluded in this study was one interviewee owing to his aggressive behaviour.

During the pilot project, a total of 5 participants out of the 9 referred to performed the entire program and they were assessed at the end of it $(\mathrm{n}=5)$.

\subsection{Instruments/Materials}

The assessment was carried out by evaluating two different aspects: on the one hand, the physical development of the participants, and on the other hand their social skills.

With all this, the items chosen to evaluate the physical development of each one of the participants have been divided 
into five main sections described below. These sections were extracted from the "Learning Standars" provided established by the Organic Law on the Improvement of the Quality of Education (LOMCE) in the field of Physical Education. The "Learning Standards" are defined in terms of observable and measurable learning aspects, using rubrics to assess the participants learning process, that is to say "an evaluation instrument based on quantitative and/or qualitative scale associated with pre-established criteria for measuring student actions during the performance of tasks and activities subsequently assessed" (Torres \& Perera, 2010, p. 142). The structure of the study is based principally on 5 situations to develop motor skills of the participants, along the structure proposed by Parlebás (1988) including individual motor behaviour, opposition actions, collaboration, and finally, adaptation of physical environment:

First section: To solve motor aspects with a variety of stimuli as well as timing and space conditionings selecting and combining the basic motor skills. These skills should be adopted effectively.

Items:

- Movement

- Jumping

- Throwing/ kicking

- Catching

- Turns

Second section: To solve typical basic technical and tactical challenges of play and physical activities with or without opposition. To put into practice principles and rules in order to solve motor aspects in an individualized and coordinated manner, moreover, to carry out the different implicit functions of play and activities.

Items:

- One-touch pass

- Carrying the ball

- Penalty shot

- Ball control

Third section: To appreciate, accept and respect their own and other's physical reality showing a reflective critical attitude.

Items:

- Can respect the diversity of physical realities and the different levels of motor skill competence among other children.

Fourth section: To express an opinion coherently adopting a critical attitude toward any difficult situation emerged from the participant or observer's perspective- in debates accepting other's opinions.

Items:

- Can explain to his partners the characteristics and development of the game carried out in the classroom.

- Can show willingness to solve conflicts in a reasonable manner.

- Can identify inappropriate behaviour during the sessions.

Fifth section: To demonstrate personal and socially responsible behaviour having self-respect and for others in physical and play activities. At the same time, children should accept the standards and rules established showing interest and individual initiative as well as teamwork.

Items:

- Can show interest to improve motor skills competence.

- Can demonstrate an autonomous and self-confident attitude.

- Can take part in the collection and organizations of materials.

- Can demonstrate good sportsmanship accepting to be part in any group and the results of sports competition.

All these items were assessed in a qualitative manner through scoring rubric, mainly based on observing practice sessions from the beginning of the program until the end. Thus, the items were assessed individually following the values of "Clearly correct", "Needs improvement" and "Not yet competent".

It is considered that the criterion determined as "Clearly correct" indicates a complete acquisition of the skills and abilities related and specified in the items; "Not yet competent" shows that there was no improvement in the acquisition 
of these skills and abilities; and finally, "Needs improvement" refers to a significant improvement concerning the starting level, whereas there is not complete acquisition of the skill.

The assessment of psychomotor development was carried out through the comparison of the data collected during the observation, taking into consideration the information from the previous assessment besides the stage of development of each participant.

On the other hand, the assessment of social skills was carried out from Goldstein's Social Skillstreaming Model (Goldstein, Sprafkin, Gershaw \& Klein, 1980) divided into six skill groups: beginning social skills, advanced social skills, dealing with feelings, alternatives to aggression, dealing with stress and planning skills.

The researchers considered that Goldstein's Social Model was one of the most complete instruments to assess and work on social skills. The most relevant items for the research were chosen and, in like manner, it was designed an observation table suitable for the implementation of this pilot project.

All these items were also assessed in a qualitative method, based on the observing practice sessions from the beginning of the program until the end, again taking into consideration the information from the previous assessment besides the stage of development of each participant.

\subsection{Data Analysis}

Once the program has been carried out, a significant change was expected with regard to the initial level of the variables studied. The analysis is largely qualitative through observing practice sessions by the staff with supervisory responsibilities, assessing the established protocols.

\section{Results}

\subsection{Motor Development}

The results of the evaluation are described following the five sections as explained above. This part is designed to serve as a guide for the performance and achievement of the different competences studied through the practice of football as a team sport.

First section: Resolve motor aspects with a variety of stimuli as well as timing and space conditionings, selecting and combining effectively the basic motor skills. The results highlight positive achievement of the items established in this section; that is, movements and turns have been satisfactorily acquired by all participants; three of the participants have achieved correct throwing and kicking, instead one of them needs improvement and only one of the children is not competent. Jumping has been achieved by two participants, while, one of them is not yet competent and the remaining participant is not competent. With regard to catching, four of the participants are developing this item and not achieved by one of the children with ASD.

Second section: Resolve typical basic technical and tactical challenges of play and physical activities with or without opposition. To put into practice principles and rules in order to solve motor aspects in an individualized and coordinated manner, moreover, to carry out the different implicit functions of play and activities.

The expectatives according to this section were largely achieved by the participants; it could be stated that ball passing and carrying the ball are the less complex skills, since the results obtained show that all participants can put into practice correct performance of these items. Goal kick has been satisfactorily achieved by three children, one participant needs improvement and the remaining one has not acquired this ability. Finally, although ball control needs more training, its development has been positive in general terms. Four of the participants have achieved correct implementation of ball control, in contrast to only one child who has not developed it.

Third section: Appreciation, acceptance and respect his/her own and other's physical reality showing a reflective critical attitude. This section focuses on fundamental attitudes towards the development of any other group games. Its unique item, that is, the ability to respect the diversity of physical realities and the different levels of motor skills competence among other children has been achieved by two participants. On the contrary, it was observed that the rest of the participants did not fulfill the item.

Fourth section: Expression of coherent opinions adopting a critical attitude towards any difficult situation emerged in debates and acceptance of other's opinion. It could be said that the results of this section are completely or partially achieved in most of the items. First of all, "Can explain to his/her partners that characteristics and development of the game carried out in the classroom" has been overcome by three participants, whereas two participants have not get it. In this case, it is important to mention that one of these children presents difficulties in oral communication. The second item ("Can show willingness to solve conflicts in a reasonable manner") is achieved by four of the five participants. The last item, closely related to the previous one ("Can identify inappropriate behaviour during the sessions") discovers a very similar results, that is, four of the five participants have achieved it. 
Fifth section: Demonstration of personal and socially responsible behaviour havingself-respect and for others in physical and play activities, at the same time, children should accept the standards and rules established showing interest and individual initiative as well as teamwork. Results demonstrated positive achievement of the items stated, in more detail, all participants show interest to improve their motor skill competence and four of the five participants demonstrated an autonomous and self-confident attitude.

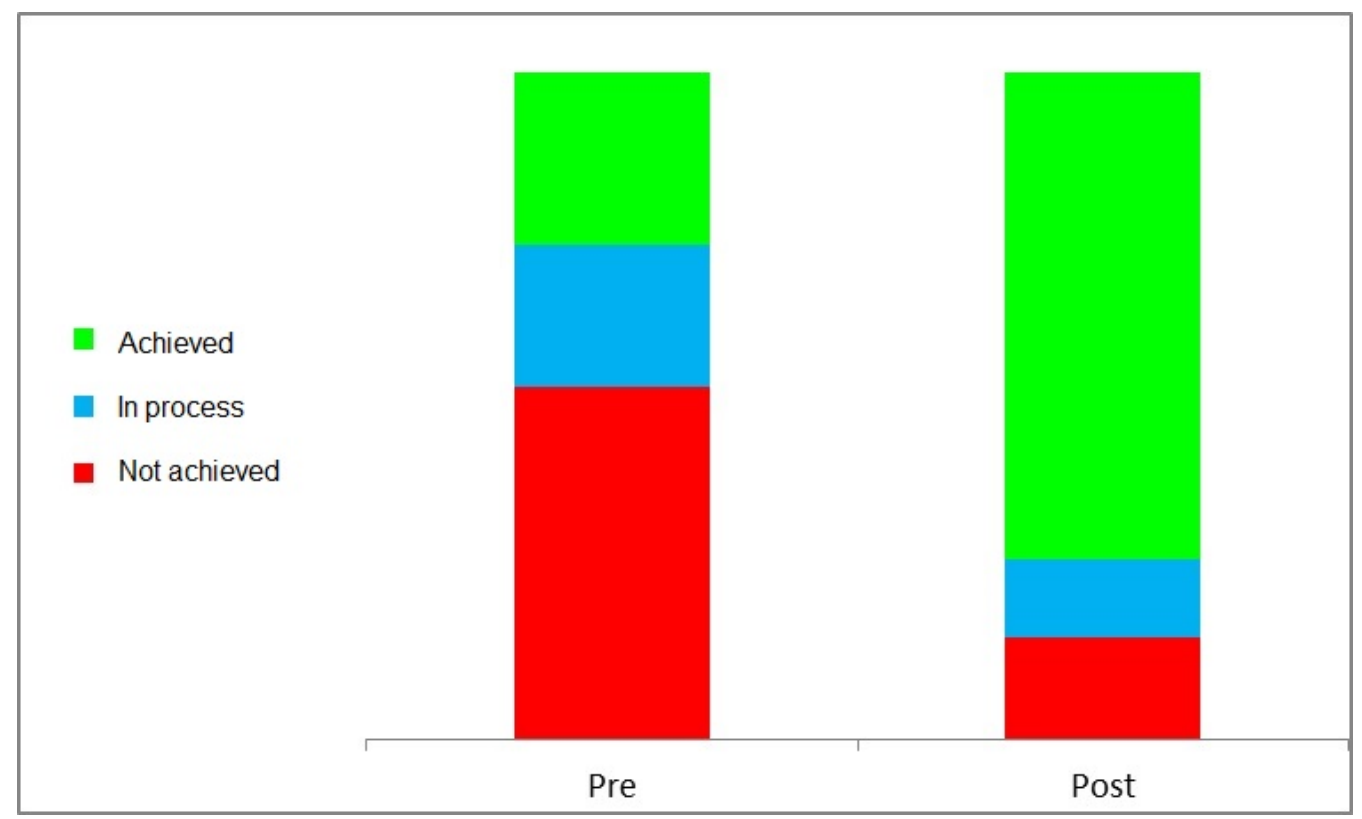

Figure 1. Assessment results of the participants' motor skills.

\subsection{Social Skills}

The results of the evaluation are described following the five sections as explained above. This part is designed to serve as a guide for the performance and achievement of the different competences studied through the practice of football as a team sport.

With regard to beginning social skills, the results obtained show that a significant improvement by three of the five participants; in most cases, the attention abilities of these children are negatively affected, so, this study reflects the necessity for further training. Two participants started and maintained conversations, while the other two participants showed poor linguistic skills. Three participants improved their ability to introduce themselves, and two of the children thanked with certain regularity. At the end of the program, the total number of participants greeted, but two of them needed some kind of support.

Two participants have shown slight improvement in advanced social skills; for example, any of them asked for help, even when they were frustrated; although, sometimes there was an attempt to make a request, this process did not occur at the end. Three participants were willing to carry out the activities from the very beginning, but at first, the other two were reluctant to participate; fortunately, this attitude was changing during the sessions. Other aspects developed by all the participants are "following and giving directions" (mainly three of the five participants). It should be mentioned that there has not been any significant improvement with regard to "dealing with feelings", probably due to the short duration of the project; meanwhile, the results show a small progress in recognition of their own feelings. Just one participant demonstrated better ability to express his own emotions. From the beginning, four of the five participants could express affection, but recognition of other's feeling still needs to be more profoundly trained. Considering anger control, it must be explained that three participants presented an acceptable level of control, one of the other participants showed a significant improvement, while the last one presented loss of control over frustration when his other partners win.

Important improvement has been obtained in alternatives to aggression by the five participants, although it is true that there were not aggressive behaviour, only two participants showed slightly aggressive conduct. The results demonstrated improvement in diverse performances, such as: share with his partners and helping each other, their capacity to control their actions and behaviour. Another significant aspect is the difficulty to comprehend and appreciate verbal jokes by participants, though occasionally one children laughed at easy-to-understand jokes. Finally, all participants except one child have avoided getting involved in disputes altogether; this child we are referring to needs further training to control frustration. 
Three of the five participants showed slight improvement with regard to "dealing with stress", particularly, one child has achieved to submit complaints. Three participants responded well to complaints and accusations. Most participants overcome shyness, and more precisely, one participant improved in this aspect. Four participants have improved their sportsmanship, although there has not been enough time to promote this aspect.

Finally, significant progress has been observed according to the planning skills of the children. Three participants took the lead, and even they were volunteer to explain some activities. It has been also shown certain improvement in respect of target-setting, mainly in those cases in which the aims were relatively simple. So, the results reflect a general improvement, although some social skills have not been considered in this pilot project.

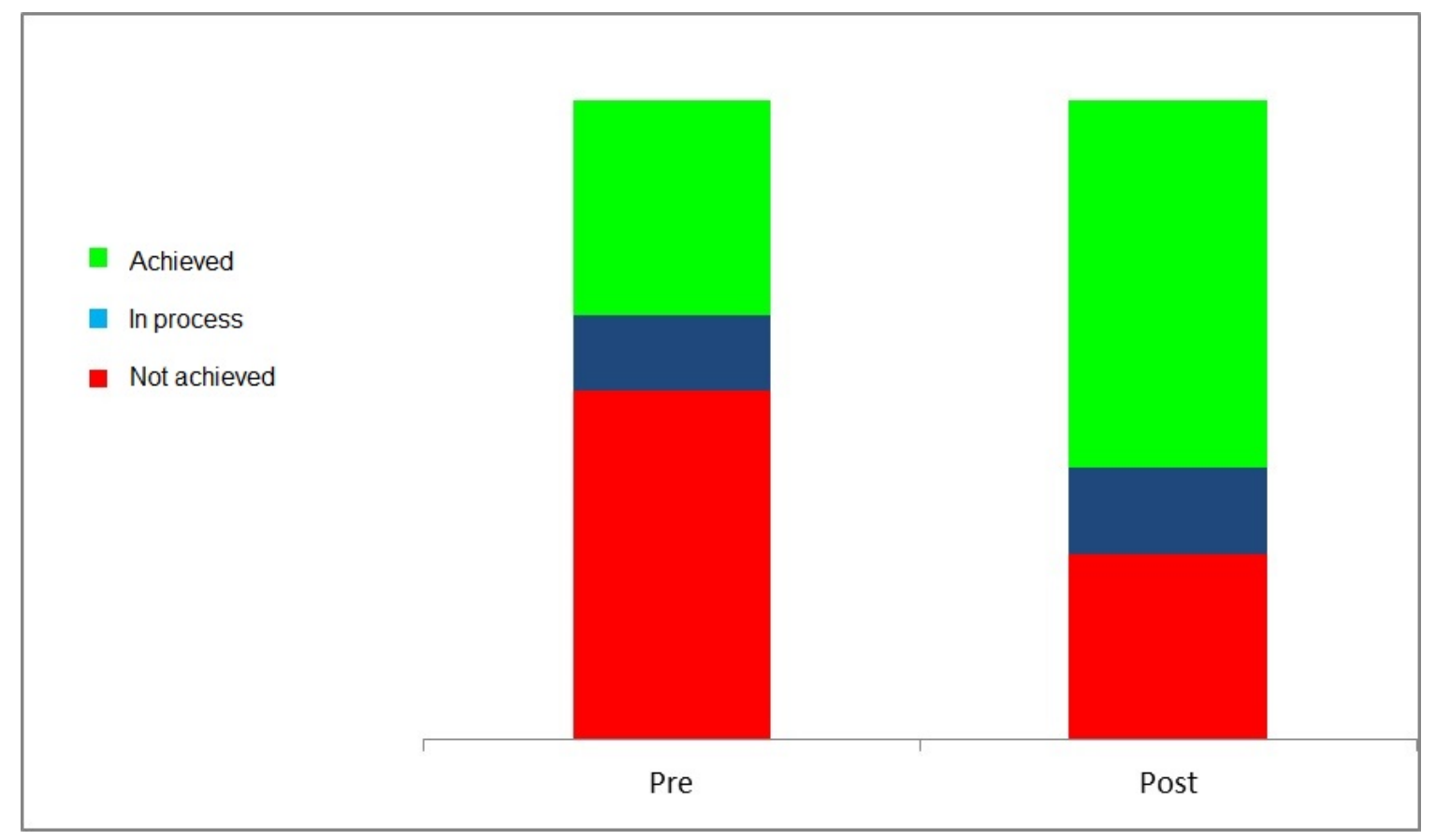

Figure 2. Assessment results of the participants' social skills.

From the table below (Table 3), it will be seen the final performance of each participant indicating how many items have not been reached at the end of the program. In this way, it could be observed the significant improvement achieved by the children during the implementation of the project as well as the comparison between participants.

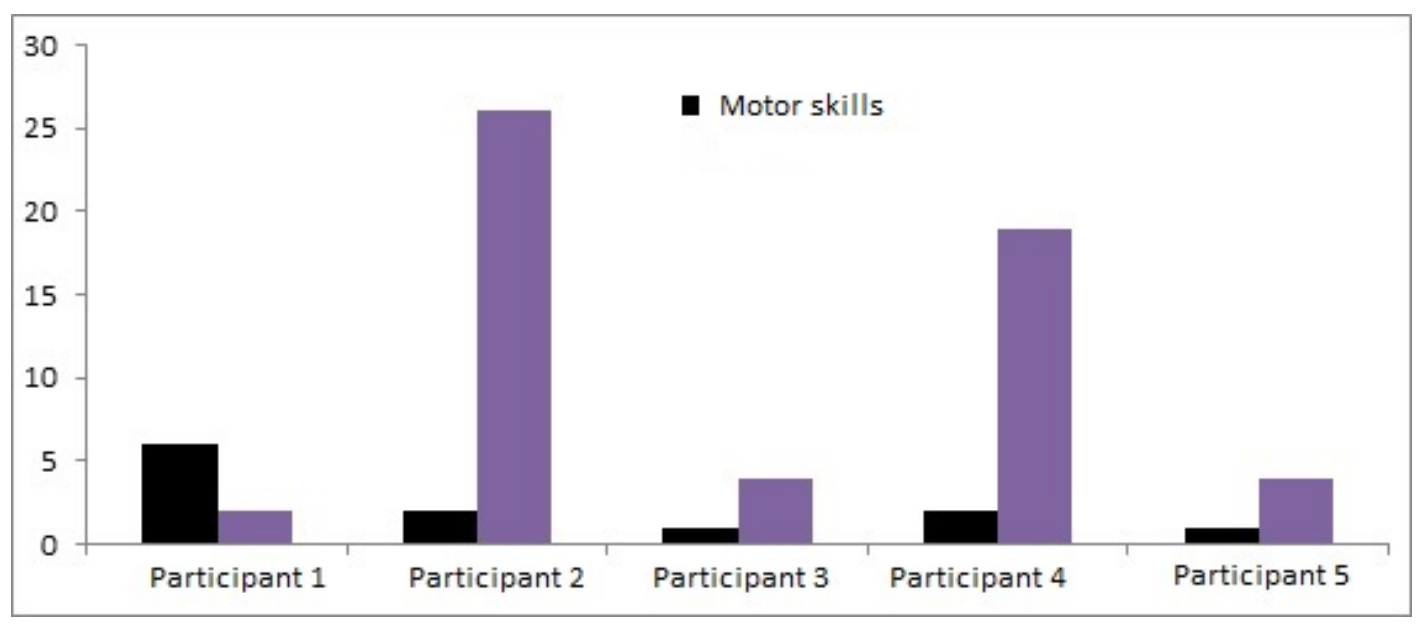

Figure 3. Assessed items labelled as "Not achieved" per participant.

\section{Discussion}

In accordance with the results obtained from the implementation of this pilot project, it may be anticipated that sports can be used as an effective tool to promote the development of psychomotor and social skills. Participants have achieved widespread and substantial improvement in physical performance, besides successful acquisition of the social 
skills under study. However, it should be taken into consideration the limitations of this study, to point out that the sample is not globally representative and the assessment was mainly subjective, hindering the generalization of the results obtained.

The research hypotheses have been verified, although it is necessary to consider that the data collection supporting this verification has been obtained in a subjective manner. Therefore, this data have to be considered with caution common in qualitative methodology.

Conversely, we have been able to ascertain a difference in the performance of two participants of the project. This information can be interpreted as a difficulty in the program adaptation to those participants owing to the limitations of these types of projects because of its widespread implementation or the consequence of the limited duration of the pilot project. To this end, future research should explore these considerations in order to discover the possible causes finding out the appropriate program adaptation.

This pilot project can be considered a complete success because of its results; however, it should be taken into account the following considerations:

Because of the limited duration of the pilot project in comparison to other similar training programs, results, though very positive, show partial progress from our expectations. Consequently, we wonder that the implementation of this sports program with longer duration will permit to obtain more significant results.

It is also important the reduced sample studied, common in this type of research representing the portion of the global population with this disorder and the highest level of autonomy; this argument does not imply that the implementation of this program in children with greater difficulties could not be effective enough. It should be also taken into consideration that the participants chosen are at a stage of development where great changes take place being relevant to the achievement of outcomes.

The data collection in this pilot project, as well as in future implementations of this program, are really new and represent a major source of scientific information about the possibility of new interventional techniques besides the improvement of the quality of life of people with ASD.

Now, diverse benefits are highlighted, for instance: the familiar context in which these programs can be carried out, that is, primary schools and high schools; the inclusive nature of the sports practice, so that children with ASD can play an active part along with other children, and, finally, the possibility to adopt football practice, achieving a relevant standardized and social positive effect on individuals with Autistic Spectrum Disorders.

\section{Acknowledgements}

The authors state that there are no conflicts of interest to the development of this research. In addition, the authors would like to thank Real Madrid Foundation for its support, infrastructures and materials provided.

\section{References}

American Psychiatric Association. (2013). Diagnostic and Statistical Manual of Mental Disorders, 5th Edition (DSM-5). Diagnostic and Statistical Manual of Mental Disorders 4th edition TR. (p. 280). https://doi.org/10.1176/appi.books.9780890425596.744053

Baron-Cohen, S. (2001). Theory of Mind in Normal Development and Autism. Prisme, 34, 174-183. Recuperado a partir de http://www.autism-community.com/wp-content/uploads/2010/11/TOM-in-TD-and-ASD.pdf

Baron-Cohen, S., Ring, H. A., Bullmore, E. T., Wheelwright, S., Ashwin, C., \& Williams, S. C. R. (2000). The amygdala theory of autism. Neuroscience and Biobehavioral Reviews, 24(3), 355-364. https://doi.org/10.1016/S0149-7634(00)00011-7

Caballo, V. E., \& Irurtia Muñiz, M. J. (2011). Entrenamiento en habilidades sociales. Técnicas de modificación de conducta. Ediciones Pirámide. Recuperado a partir de http://dialnet.unirioja.es/servlet/articulo?codigo=3659451

Castelo, J. F. F. (1999). Fútbol: estructura y dinámica del juego. Recuperado a partir de https://books.google.com/books?hl=es\&lr=\&id=MpMUGRD9SDYC\&pgis=1

Cos, F., Cos, M. Á., Buenaventura, L., Pruna, R., \& Ekstrand, J. (2010). Modelos de análisis para la prevención de lesiones en el deporte. Estudio epidemiológico de lesiones: el modelo Union of European Football Associations en el fútbol. Apunts. Medicina de l'Esport, 45(166), 95-102. https://doi.org/10.1016/j.apunts.2010.02.007

Díez-Cuervo, A., Muñoz-Yunta, J. A., Fuentes-Biggi, J., Canal-Bedia, R., Idiazábal-Aletxa, M. A., Palacios, S., ... Sanidad, D. (2005). Guía de buena práctica para el diagnóstico de los trastornos del espectro autista. Revista neurológica, 41(5), 299-310. https://doi.org/10.4321/S1130-14732009000400001 
Dosil, J. (2004). Psicología de la actividad fisica y del deporte. Recuperado a partir de https://books.google.es/books/about/Psicolog\%C3\%ADa_de_la_actividad_f\%C3\%ADsica_y_de.html?id=MQNB AAAACAAJ\&pgis $=1$

Educación, M. D. E., \& Deporte, C. Y. (2014). Boletín oficial del estado, 19349-19420.

Estado, J. G. del. LEY 47/2003, de 26 de noviembre GRAL. PRESUPUESTARIA (2003).

Fisher, N., \& Happé, F. (2005). A training study of theory of mind and executive function in children with autistic spectrum disorders. Journal of Autism and Developmental Disorders, 35(6), 757-771. https://doi.org/10.1007/s10803-005-0022-9

Frith, U. (2001). Mind blindness and the brain in autism. Neuron, 32(6), 969-979. https://doi.org/10.1016/S0896-6273(01)00552-9

Frith, U., \& Hill, E. (s. f.). Autism: Mind and brain.

Fuentes-Biggi, J., Ferrari-Arroyo, M. J., Boada-Muñoz, L., Touriño-Aguilera, E., Martos, J., \& Posada-de-la-Paz, M. (2006). Guía de buena práctica para la investigación de los trastornos del espectro autista. Rev neurol, 43(7), 425-438. https://doi.org/10.4321/S1130-14732009000400001

Fuentes-Biggi, J., Ferrari-Arroyo, M. J., Boada-Muñoz, L., Touriño-Aguilera, E., Martos-Pérez, J., Paz, M. P., ... Sanidad, M. De. (2006). Guía de buena práctica para el tratamiento de los trastornos del espectro autista. Revista de Neurología, 43(7), 425-438.

Goldstein, A. P., Sprafkin, R. P., Gershaw, N. J., \& Klein, P. (1980). adolescent: social skills training through structured learning. Teaching social skills to children : innovative approaches / edited by Gwendolyn Cartledge and JoAnne Fellows Milburn. Recuperado a partir de http://agris.fao.org/agris-search/search.do?recordID=US201302643959

Gómez López, M., Valero Valenzuela, A., Peñalver López, I., \& Velasco da Silva, M. (2008). El trabajo de la motricidad en la clase de Educación Física con niños autistas a través de la adaptación del lenguaje Benson Schaeffer. Revista Iberoamericana de educación. Servicio de Publicaciones. Recuperado a partir de $\mathrm{http} / /$ dialnet.unirioja.es/servlet/articulo? codigo $=2661769$ \&info $=$ resumen\&idioma $=$ SPA

Gutiérrez Sanmartín, M. (2004). El valor del deporte en la educación integral del ser humano. Revista de educación, (335), 105-126. Recuperado a partir de http://dialnet.unirioja.es/servlet/articulo?codigo=1066536\&info=resumen\&idioma=ENG

Ibáñez López, P., \& Mudarra Sánchez, M. J. (2004). Relaciones sociales de personas con discapacidad, en el Ocio y Tiempo libre. Revista Española de Pedagogía, 229, 521-540.

Jasmin, E., Couture, M., McKinley, P., Reid, G., Fombonne, E., \& Gisel, E. (2009). Sensori-motor and daily living skills of preschool children with autism spectrum disorders. Journal of Autism and Developmental Disorders, 39(2), 231-241. https://doi.org/10.1007/s10803-008-0617-z

Lagar García, J. A. (2003). Deporte y discapacidad. Redactor Nacional, De Radio España, 1-16.

Lloyd, M., MacDonald, M., \& Lord, C. (2013). Motor skills of toddlers with autism spectrum disorders. Autism : the International Journal of Research and Practice, 17(2), 133-146. https://doi.org/10.1177/1362361311402230

Martínez, J. M. O., Menlle, J. V., Hernández, A. A., Rodríguez, Á. L., Martín, M. M., \& Buendía, R. V. (1996). El alumnado con discapacidad I: una propuesta de integración. Ministerio de Educación y Ciencia. Recuperado a partir de http://dialnet.unirioja.es/servlet/libro?codigo $=560055$

Martínez, Ma A., \& Cuesta, J.L. y cols (2013). Todo sobre autismo. $2^{a}$ Edición. Los trastornos del Espectro Autista (TEA). Guia completa basada en la ciencia y en la experiencia. Altaria S.L.

Memari, A. H., Ghaheri, B., Ziaee, V., Kordi, R., Hafizi, S., \& Moshayedi, P. (2013). Physical activity in children and adolescents with autism assessed by triaxial accelerometry. Pediatric Obesity, 8(2), 150-158. https://doi.org/10.1111/j.2047-6310.2012.00101.x

Méndez, D., Fernández-Rio, J., Méndez-Giménez, A., Prieto, J.A. (2015). Análisis de los currículos autonómicos LOMCE de Educación Física en Educación Primaria. Assessment of the LOMCE state curricula on Primary Education Physical Education. Retos, 282015 (2 Semestre). Federación Española de Asociaciones de Docentes de Educación Física (FEADEF). Recuperado a partir de http://www.redalyc.org/html/3457/345741428003/

Nuñez Del Arco, C. R. G. (s. f.). Habilidades sociales, clima social familiar y rendimiento académico en estudiantes universitarios. Liberabit, 11(11), 63-74. Recuperado a partir de

http://pepsic.bvsalud.org/scielo.php?script=sci_arttext\&pid=S1729-48272005000100008\&lng=pt\&nrm=iso\&tlng=es 
Obrusnikova, I., \& Cavalier, A. R. (2010). Perceived Barriers and Facilitators of Participation in After-School Physical Activity by Children with Autism Spectrum Disorders. Journal of Developmental and Physical Disabilities, 23(3), 195-211. https://doi.org/10.1007/s10882-010-9215-z

Oxford. (2010). Oxford Dictionaries. Recuperado a partir de http://oxforddictionaries.com/definition/english/paradigm?q=paradigm

Pan, C. Y. (2008). Objectively measured physical activity between children with autism spectrum disorders and children without disabilities during inclusive recess settings in Taiwan. Journal of autism and developmental disorders, 38(7), 1292-1301. https://doi.org/10.1007/s10803-007-0518-6

Pan, C. Y., \& Frey, G. C. (2006). Physical activity patterns in youth with autism spectrum disorders. Journal of autism and developmental disorders, 36(5), 597-606. https://doi.org/10.1007/s10803-006-0101-6

Puerta, G. (2005). Los Juegos Y Deportes The Development Of The Conscience Of Rule In The Games And Sports, 5, 238-269.

Ramachandran, S., Deshpande, O., Roseman, C. C., Rosenberg, N. A., Feldman, M. W., \& Cavalli-Sforza, L. L. (2005). Support from the relationship of genetic and geographic distance in human populations for a serial founder effect originating in Africa. Proceedings of the National Academy of Sciences of the United States of America, 102(44), 15942-15947. https://doi.org/10.1073/pnas.0507611102

Real Academia Española. (2014). Diccionario De La Lengua Española. Recuperado a partir de http://lema.rae.es/drae/?val=practica

Smith, T., Scahill, L., Dawson, G., Guthrie, D., Lord, C., Odom, S., ... Wagner, A. (2007). Designing research studies on psychosocial interventions in autism. Journal of Autism and Developmental Disorders, 37(2), 354-366. https://doi.org/10.1007/s10803-006-0173-3

Staples, K. L., \& Reid, G. (2010). Fundamental movement skills and autism spectrum disorders. Journal of Autism and Developmental Disorders, 40(2), 209-17. https://doi.org/10.1007/s10803-009-0854-9

Vonder Hulls, D. S., Walker, L. K., \& Powell, J. M. (2006). Clinicians' Perceptions of the Benefits of Aquatic Therapy for Young Children with Autism. Physical \& Occupational Therapy in Pediatrics, 26(1-2), 13-22. https://doi.org/10.1080/J006v26n01_03

\section{Copyrights}

Copyright for this article is retained by the author(s), with first publication rights granted to the journal.

This is an open-access article distributed under the terms and conditions of the Creative Commons Attribution license which permits unrestricted use, distribution, and reproduction in any medium, provided the original work is properly cited. 